\title{
Short communication: A comparison of biofilm development on stainless steel and modified-surface plate heat exchangers during a 17-h milk pasteurization run
}

\author{
Shivali Jindal,, Sanjeev Anand, ${ }^{* 1}$ Lloyd Metzger, ${ }^{*}$ and Jayendra Amamcharla† \\ *Midwest Dairy Foods Research Center, Department of Dairy and Food Science, South Dakota State University, Brookings 57007 \\ †Department of Animal Sciences and Industry/Food Sciences Institute, Kansas State University, Manhattan 66506
}

\section{ABSTRACT}

Flow of milk through the plate heat exchanger (PHE) results in denaturation of proteins, resulting in fouling. This also accelerates bacterial adhesion on the PHE surface, eventually leading to the development of biofilms. During prolonged processing, these biofilms result in shedding of bacteria and cross-contaminate the milk being processed, thereby limiting the duration of production runs. Altering the surface properties of PHE, such as surface energy and hydrophobicity, could be an effective approach to reduce biofouling. This study was conducted to compare the extent of biofouling on native stainless steel (SS) and modified-surface [Ni-P-polytetrafluoroethylene (PTFE)] PHE during the pasteurization of raw milk for an uninterrupted processing run of $17 \mathrm{~h}$. For microbial studies, raw and pasteurized milk samples were aseptically collected from inlets and outlets of both PHE at various time intervals to examine shedding of bacteria in the milk. At the end of the run, 3M quick swabs (3M, St. Paul, $\mathrm{MN}$ ) and ATP swabs (Charm Sciences Inc., Lawrence, MA) were used to sample plates from different sections of the pasteurizers (regeneration, heating, and cooling) for biofilm screening and to estimate the efficiency of cleaning in place, respectively. The data were tested for ANOVA, and means were compared. Modified PHE experienced lower mesophilic and thermophilic bacterial attachment and biofilm formation (average log 1.0 and $0.99 \mathrm{cfu} / \mathrm{cm}^{2}$, respectively) in the regenerative section of the pasteurizer compared with SS PHE (average log 1.49 and 1.47, respectively). Similarly, higher relative light units were observed for SS PHE compared with the modified PHE, illustrating the presence of more organic matter on the surface of SS PHE at the end of the run. In addition, at h 17 , milk collected from the outlet

Received October 21, 2017.

Accepted December 4, 2017.

${ }^{1}$ Corresponding author: sanjeev.anand@sdstate.edu of SS PHE showed plate counts of $5.44 \mathrm{cfu} / \mathrm{cm}^{2}$, which were significantly higher than those for pasteurized milk collected from modified PHE (4.12 $\left.\mathrm{log} \mathrm{cfu} / \mathrm{cm}^{2}\right)$. This provided further evidence in favor of the modified PHE achieving better microbial quality of pasteurized milk in long process runs. Moreover, because cleaning SS PHE involves an acid treatment step, whereas an alkali treatment step is sufficient for the modified-surface PHE, use of the latter is both cost and time effective, making it a better surface for thermal processing of milk and other fluid dairy products.

Key words: biofilm, stainless steel, plate heat exchanger, pasteurization, cleaning

\section{Short Communication}

Milk is considered an ideal medium for growth of many pathogenic and spoilage-causing bacteria because it contains nutritional components essential for their growth (Degeest and De Vuyst, 1999; Cherif-Antar et al., 2016). Thermal processes, such as pasteurization of milk, are used to reduce spoilage bacteria as well as pathogens in order to provide protection from illness (Visser and Jeurnink, 1997). Plate heat exchangers (PHE), which have a stainless steel (SS; SS-316) surface, are used for pasteurizing milk and other products in the dairy industry (Shah et al., 1988). As milk flows through PHE, milk proteins denature as a result of heating of milk and stick to the equipment surface (Rosmaninho and Melo, 2006). In an earlier study, Bouman et al. (1982) observed the fouling of PHE to be greater in the regeneration section of the pasteurizer. The composition of the deposit with a temperature reaching $57^{\circ} \mathrm{C}$ after $12 \mathrm{~h}$ of processing was found to be $30 \mathrm{mg} /$ plate for phosphorus, $51 \mathrm{mg} /$ plate for calcium, and $52 \mathrm{mg} /$ plate for protein. However, the composition changed significantly in the heating section where a temperature of $70^{\circ} \mathrm{C}$ was maintained and was found to be $36 \mathrm{mg} /$ plate for phosphorus, $95 \mathrm{mg} /$ plate for calcium, and $133 \mathrm{mg} /$ plate for protein. Further, the fouling due to protein and mineral deposits on the 
surface of PHE during pasteurization also accelerates bacterial adhesion to the surfaces, leading to biofilm development. Thermophiles were reported by Hinton et al. (2002) at a level of $10^{5} \mathrm{cfu} / \mathrm{cm}^{2}$ on fouled surfaces, whereas no bacterial activity was detected on the clean surface. An important source of microbial crosscontamination in the dairy industry is the formation of microbial biofilm during milk storage and processing due to the adherence of bacterial contaminants on SS surfaces (Flint et al., 1997). Development of biofilms in milk processing environments leads to increased opportunity for microbes to cross-contaminate the processed dairy products. Moreover, spoilage and pathogenic bacteria trapped in biofilms are protected from sanitizers due to multispecies cooperation and the presence of extracellular polymeric substances, which result in their survival (Watnick and Kolter, 2000). Rapid fouling of PHE is thus undesirable for both economic and technical reasons. According to a study conducted by Van Asselt et al. (2005), 80\% of the total production cost in dairy processing industries is attributed to fouling and cleaning. Further, the production run times are limited due to both shedding of bacteria in the product, leading to microbiological concerns, and restoring the heat transfer characteristics of PHE (Sandu and Singh, 1991). It also has been reported that metal surfaces get corroded (Bryers, 1987; Gupta and Anand, 2017) due to metabolic activity of the microorganisms present in the biofilm.

The initial establishment of biofilm highly depends on the properties of the surface material, such as surface energy and hydrophobicity (Flint et al., 1997). Many researchers have reported that bacterial adhesion is reduced with the lowering of surface energy and enhanced surface hydrophobicity (Fletcher and Loeb, 1979; Pringle and Fletcher, 1983; Tsibouklis et al., 2000; Liu et al., 2017). Hence, it is of high relevance to modify the SS surface and to use antimicrobial coatings to have less deposition, bacterial adhesion, and establishment of biofilms. One of our recent studies (Jindal et al., 2016) using modified coupons revealed that an SS-316 surface modified with an Ni-P-polytetrafluoroethylene (PTFE) blend supports lower bacterial adherence, consequently resulting in minimal biofilm formation. A native SS surface with the highest value of surface energy $(42.94 \pm 0.67 \mathrm{mN} / \mathrm{m})$ recorded a maximum bacterial attachment of $\log 5.11 \pm 0.03$, whereas an Ni-P-PTFE modified surface with the least surface energy $(15.96 \pm 1.21 \mathrm{mN} / \mathrm{m})$ exhibited lower bacterial attachment $(3.15 \pm 0.04)$. Results from this study were promising; however, the experiments were conducted on coupons in a laboratory-scale static environment. As a follow-up, the purpose of this study was to investigate the extent of biofouling on native (SS) and modified
(Ni-P-PTFE) PHE under dynamic conditions for an extended run time of $17 \mathrm{~h}$.

The 2 pasteurizers used for this study included a native (SS) and an Ni-P-PTFE modified-surface PHE (AGC Heat Transfer, Portland, OR). Milk was allowed to flow continuously through both pasteurizers for $17 \mathrm{~h}$ to simulate the conditions encountered in a typical dairy plant. Prior to the pasteurization step, the incoming raw milk was split into 2 balance tanks. At the end of pasteurization, both PHE were flushed with water and were dismantled for biofilm sampling. Plates were reassembled in both PHE for cleaning in place (CIP) and were then dismantled again to check the efficiency of CIP. Two-stage CIP treatment followed, which involved the use of sodium hydroxide and an acid wash of nitric acid for native PHE. The Ni-P-PTFE modified-surface PHE, being sensitive to the acid treatment, was treated with only alkali during the CIP cycle, as recommended by the manufacturer.

To study the microbial changes, milk samples were collected from both the balance tanks (raw milk sample) and outlets (pasteurized milk sample) of both pasteurizers at the start of the run (h 0 ) and at hourly intervals from h 11 until the completion of the run (h 17). Raw and pasteurized milk samples were maintained at $4^{\circ} \mathrm{C}$ from collection to completion of analysis. Appropriate serial dilutions were made aseptically and plated on plate count agar, followed by incubation at $32^{\circ} \mathrm{C}$ for $48 \mathrm{~h}$. Colony-forming units were calculated, and the counts were reported as log colony-forming units per milliliter (Wehr and Frank, 2004).

At the end of the run, when PHE were flushed with water, 3M quick swabs (3M, St. Paul, MN) were used to recover biofilms from the regeneration section. Standard protocols were followed to enumerate mesophiles and thermophiles embedded in the 17-h-old biofilms. To validate the surface cleanliness of each section of both PHE, Charm's ATP swabs (Charm Sciences Inc., Lawrence, MA) were used. A bioluminescence luminometer (Charm Sciences Inc.) was used to measure the relative light units (RLU). Matrix-assisted laser desorption/ ionization time of flight (MALDI-TOF) was used to identify the selected isolates from raw milk, pasteurized milk, and the surface of both PHE. It is a reliable method for identification of bacteria and examines ribosomal proteins based on mass spectrophotometry. The bacterial counts were analyzed using ANOVA, and means were compared.

The results obtained in this study are presented in Figures 1 to 5 . We observed that the SPC started to increase in the pasteurized milk samples after $\mathrm{h} 11$. The SPC at h 11 for the pasteurized milk of native PHE (log $\left.2.54 \mathrm{cfu} / \mathrm{cm}^{2}\right)$ was far higher compared with that for the modified-surface PHE $(<1.0 \log )$; however, the rate 


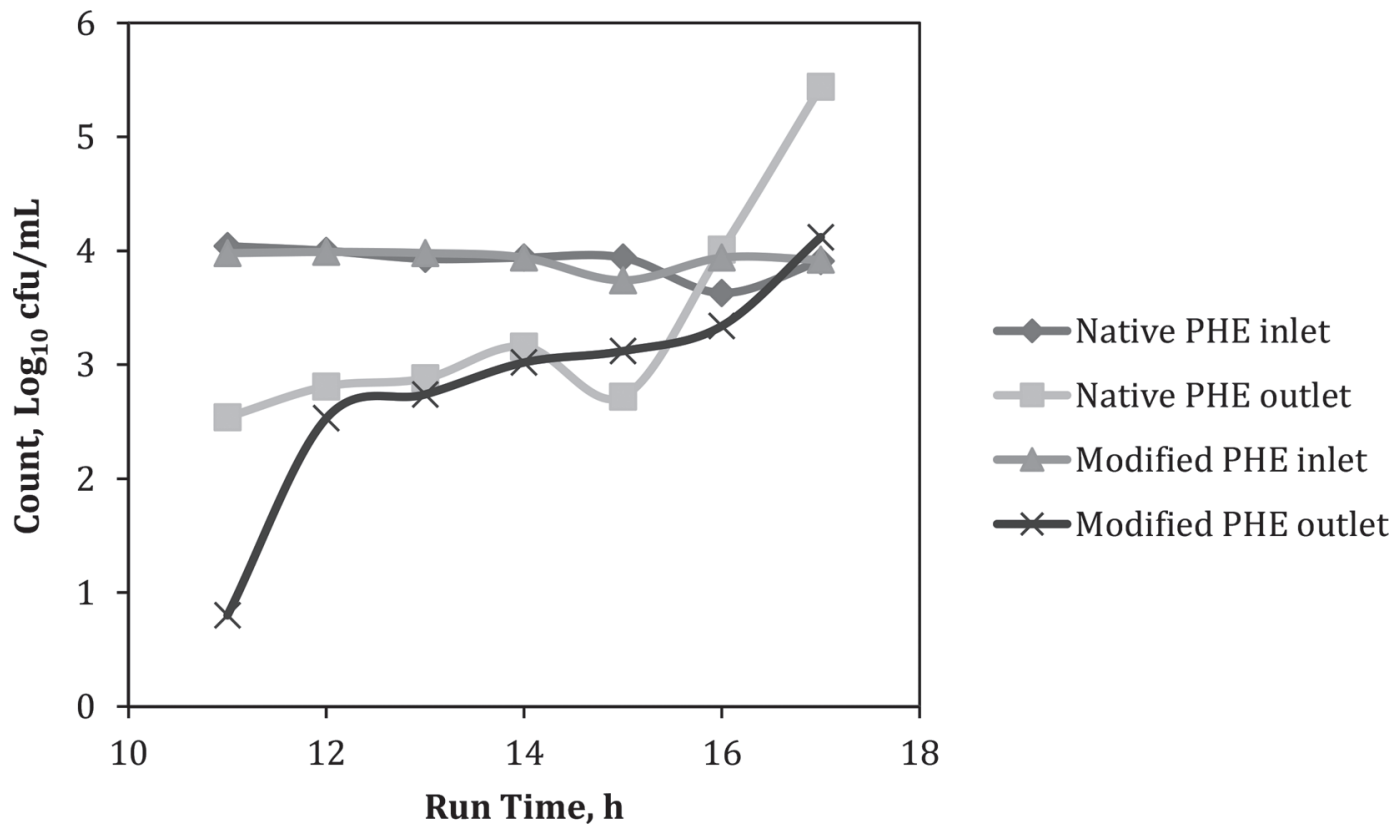

Figure 1. Standard plate count of raw and pasteurized milk from native and modified plate heat exchangers (PHE). Values are an average of duplicate analysis.

of growth is steeper for the modified PHE compared with the steady count for the native PHE. This trend is understandable because the bacterial counts for the pasteurized milk obtained from native PHE started to increase (after $\mathrm{h}$ 10) long before those for the pasteurized milk obtained from modified PHE (counts increased after $\mathrm{h}$ 11). Hence, by $\mathrm{h} 11$, the SPC for pasteurized milk obtained from native PHE had already increased, whereas the SPC for the pasteurized milk obtained from modified PHE had just started to increase, resulting in its steeper slope after h 11 . Further, past h 15, SPC increased sharply in the native PHE. Due to this sudden increase, by h 17 the SPC increased to log 5.44 $\mathrm{cfu} / \mathrm{mL}$ - far more than that for the modified PHE (log $4.12 \mathrm{cfu} / \mathrm{cm}^{2}$; Figure 1). Similar trends of rapid increase in the later part of the run were also reported in a previous study by Lehmann et al. (1992). In that study, the bacterial count was reported to increase slightly $\left(7 \times 10^{3} / \mathrm{mL}\right.$ to $\left.2 \times 10^{4} / \mathrm{mL}\right)$ in the pasteurized milk during the initial $10 \mathrm{~h}$ of operation and more rapidly $(2$ $\times 10^{6} / \mathrm{mL}$ ) during the remaining $21 \mathrm{~h}$ of operation. One of the reasons for the rapid increase in bacterial counts at the later stage of the pasteurization run could be the shedding of biofilm-entrapped bacteria into the product stream. Flint et al. (2001) also reported that the bacteria trapped in biofilms of Geobacillus stearothermophilus could shed into the milk passing over them. In another study, Bouman et al. (1982) examined the adhesion of Streptococcus thermophilus on the surface of PHE and found that there was much greater bacterial adhesion on the regeneration side of the pasteurizer. In our study, by quantifying the cells adhering to the regeneration section of both PHE (Figure 2), we found that the regeneration section of the native PHE attracted more bacteria $\left(\log 1.48 \mathrm{cfu} / \mathrm{cm}^{2}\right)$ than that of the modified PHE $\left(\log 0.995 \mathrm{cfu} / \mathrm{cm}^{2}\right)$. This is likely due to less conditioning of the modified surface due to the reduced amount of milk solids sticking to its surface compared with the native SS surface. Rosmaninho et al. (2007) reported that the Ni-P-PTFE coated surface promoted less deposit buildup. In another study, Zhao (2004) stated that these coatings hindered bacterial adhesion by 82 to $97 \%$.

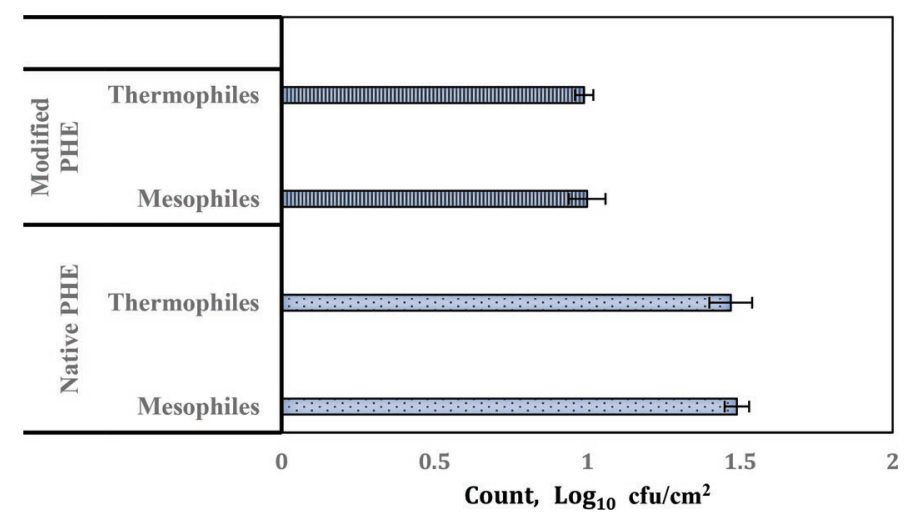

Figure 2. Biofilm counts in the regeneration section of native and modified plate heat exchangers (PHE). Values are an average of duplicate analysis $\pm \mathrm{SE}$. Color version available online. 
On comparing the biofilm-trapped bacteria from the regeneration sections of both $\mathrm{PHE}$, mesophiles were slightly higher in the native PHE $\left(\log 1.49 \mathrm{cfu} / \mathrm{cm}^{2}\right)$ than in the modified-surface PHE $\left(\log 1.0 \mathrm{cfu} / \mathrm{cm}^{2}\right)$. The trend was similar for the thermophiles, which showed biofilm-trapped bacteria counts of log $1.47 \mathrm{cfu} /$ $\mathrm{cm}^{2}$ in native PHE compared with $\log 0.99 \mathrm{cfu} / \mathrm{cm}^{2}$ in modified PHE (Figure 2). This indicates that the bacteria isolated from the biofilms formed in the regeneration section of the pasteurizer can potentially survive as well as multiply during the long pasteurization runs. A previous study conducted by Sharma and Anand (2002) demonstrated the active multiplication of both mesophiles (6 isolates in a prepasteurized line to 29 isolates in a postpasteurized line) and thermophiles (1 isolate in a prepasteurized line to 6 isolates in a postpasteurized line) during the commercial pasteurization of milk. It also suggested the ability of mesophiles and thermophiles to survive and multiply in the pasteurizer.

The species identification studies, carried out using MALDI-TOF, revealed some similarities between the types of bacteria in the biofilms developed in the regeneration section of both PHE and the ones isolated from the milk samples (Figure 3 and 4 ). There were fewer types of predominant species in the biofilms compared with the milk samples; this must be a result of the selection and predominance of some types over others during the pasteurization process. Twenty-one isolates obtained from the milk samples and biofilm swabs were speciated using MALDI-TOF. Isolates from balance tank were identified as Candida krusel, Pseudomonas azotoformans, Staphylococcus aureus, Escherichia coli, Bacillus licheniformis, Pseudomonas rhodesiae, Pseudomonas chlororaphis, Pseudomonas putida, Acinetobacter sp., Bacillus altitudinis, Pseudomonas chlororaphis, Lactococcus garvieae, Bacillus cereus, Streptomyces, Staphylococcus warneri, and Bacillus sonorensis. On the other hand, Streptomyces, Staphylococcus warneri, Bacillus cereus, Bacillus licheniformis, Bacillus sonorensis, Brevibacillus parabrevis, Kocuria rhizophila, Streptococcus salivarium ssp., and Bacillus pumilus were isolated from the surface biofilms of the regeneration section of both PHE. After h 10 it was found that bacteria gradually increased in the product stream, and the isolates from pasteurized milk were identified as Bacillus pumilus, Pseudomonas putida, Staphylococcus aureus, Bacillus licheniformis, and Bacillus cereus.

The relative cleaning efficiency was monitored by measuring RLU using a bioluminescence luminometer (Charm Sciences Inc.) after cleaning the surfaces of both native and modified-surface PHE at the end of the 17-h run (Figure 5). These RLU were observed to be around 10 times higher for native PHE compared with the modified PHE. This clearly indicates the presence

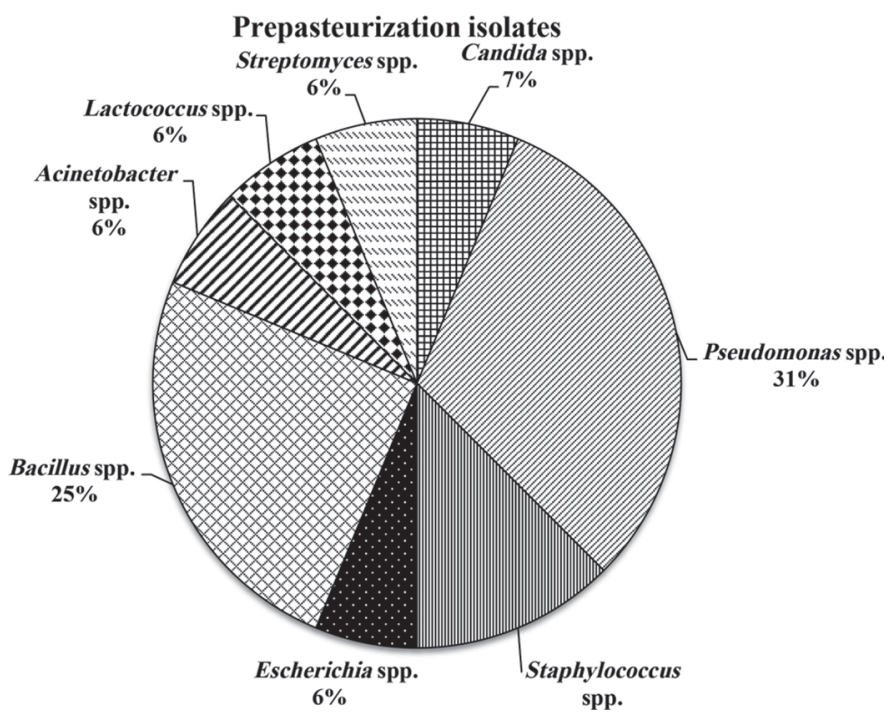

Figure 3. Isolates identified from raw milk by matrix-assisted laser desorption/ionization time of flight.

of more OM on the surface of native PHE after CIP, making it highly vulnerable to bacterial attachment and biofilm formation. Because ATP swabs detect the total ATP present on the surface and do not differentiate between ATP from bacterial cells and ATP from OM, direct comparison of RLU and colony-forming units to biofilms is not feasible. However, the overall fouling was clearly established to be higher for the native PHE compared with the modified PHE from organic fouling and biofouling observations. Furthermore, in the native pasteurizer, the highest RLU counts were observed in the regeneration section, whereas the lowest RLU counts were observed in the cooling section after

\section{Postpasteurization Isolates}

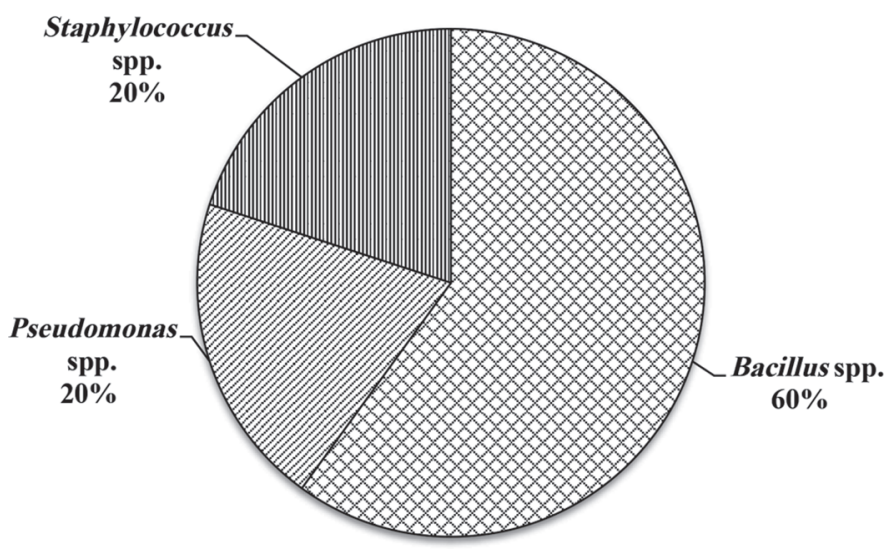

Figure 4. Isolates identified from pasteurized milk by matrix-assisted laser desorption/ionization time of flight. 


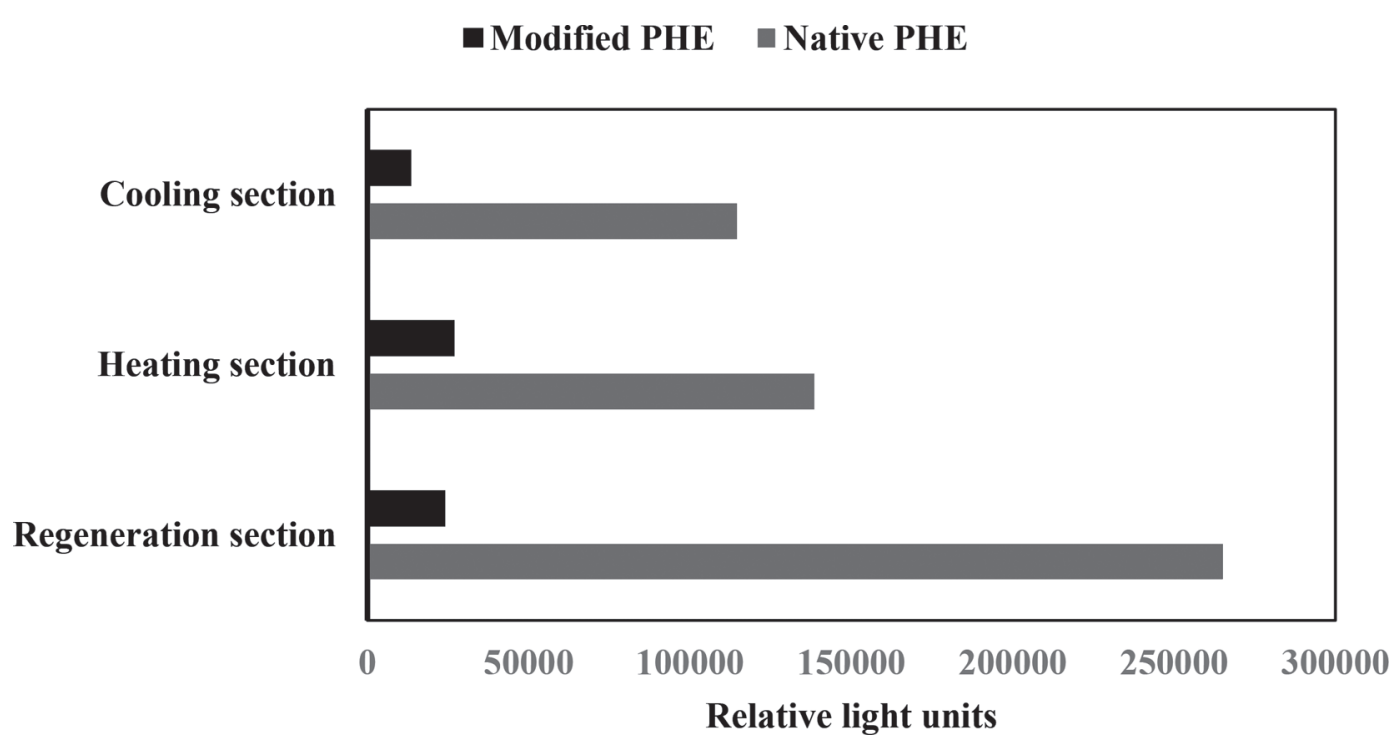

Figure 5. Relative light units on native and modified stainless steel surface after cleaning. PHE $=$ plate heat exchangers. Values are an average of duplicate analysis.

pasteurization. On the other hand, in the modified pasteurizer, there were significantly lower RLU in all sections. Within those low RLU, the higher RLU counts were observed in the heating section compared with the cooling section of the modified PHE. An important observation from the RLU counts obtained indicates the presence of the least amount of OM after cleaning (as indicated by low RLU counts) in the cooling section of both the native and modified PHE. This is apparent from the fact that the heating and regeneration sections of the pasteurizers involve the denaturation of protein (as opposed to the cooling section) that stick to their surfaces and pose a later challenge during the cleaning process.

In conclusion, this study supports the superiority of modified-surface (Ni-P-PTFE) PHE in terms of lower bacterial adhesion compared with the native PHE. The lower fouling would thus be helpful in conducting longer production runs without any cleaning interruptions. Moreover, because cleaning native PHE involves an acid treatment step, whereas only an alkali treatment step is required for modified-surface PHE, use of the latter is both cost and time effective, making it a better surface compared with the former.

\section{ACKNOWLEDGMENTS}

This study was financially supported by Dairy Management Inc. (Rosemont, IL) and administered by the Dairy Research Institute (Rosemont, IL). The authors acknowledge the support of the Agricultural Experimentation Station, South Dakota State Univer- sity (Brookings), in conducting this study. AGC Heat Transfer (Portland, OR) is acknowledged for donating Ni-P-PTFE modified stainless steel plate heat exchanger plates. This study is not an endorsement of any commercial product and is for academic purposes only.

\section{REFERENCES}

Bouman, S., D. B. Lund, F. M. Driessen, and D. G. Schmidt. 1982. Growth of thermoresistant streptococci and deposition of milk constituents on plates of heat exchangers during long operating times. J. Food Prot. 45:806-812.

Bryers, J. D. 1987. Biologically active surfaces: Processes governing the formation and persistence of biofilms. Biotechnol. Prog. 3:57-68.

Cherif-Antar, A., B. Moussa-Boudjemâa, N. Didouh, K. Medjahdi, B. Mayo, and A. B. Flórez. 2016. Diversity and biofilm-forming capability of bacteria recovered from stainless steel pipes of a milkprocessing dairy plant. Dairy Sci. Technol. 96:27-38.

Degeest, B., and L. De Vuyst. 1999. Indication that the nitrogen source influences both amount and size of exopolysaccharides produced by Streptococcus thermophilus LY03 and modelling of the bacterial growth and exopolysaccharide production in a complex medium. Appl. Environ. Microbiol. 65:2863-2870.

Fletcher, M., and G. Loeb. 1979. Influence of substratum characteristics on the attachment of a marine pseudomonad to solid surfaces. Appl. Environ. Microbiol. 37:67-72.

Flint, S., P. Bremer, and J. Brooks. 1997. Biofilms in dairy manufacturing plant-Description, current concerns and methods of control. Biofouling 11:81-97.

Flint, S., J. Palmer, K. Bloemen, J. Brooks, and R. Crawford. 2001. The growth of Bacillus stearothermophilus on stainless steel. J. Appl. Microbiol. 90:151-157.

Gupta, S., and S. Anand. 2017. Induction of pitting corrosion on stainless steel (grades 304 and 316) used in dairy industry by biofilms of common sporeformers. Int. J. Dairy Technol. https://doi.org/10 .1111/1471-0307.12444.

Hinton, A., K. Trinh, J. Brooks, and G. Manderson. 2002. Thermophile survival in milk fouling and on stainless steel during cleaning. Food Bioprod. Process. 80:299-304. 
Jindal, S., S. Anand, K. Huang, J. Goddard, L. Metzger, and J. Amamcharla. 2016. Evaluation of modified stainless steel surfaces targeted to reduce biofilm formation by common dairy related sporeformers. J. Dairy Sci. 99:9502-9513.

Lehmann, F., P. Russell, L. Solomon, and K. Murphy. 1992. Bacterial growth during continuous milk pasteurisation. Aust. J. Dairy Technol. 47:28-32.

Liu, D. Z., S. Jindal, J. Amamcharla, S. Anand, and L. Metzger. 2017. Evaluation of a sol-gel-based stainless steel surface modification to reduce fouling and biofilm formation during pasteurization of milk. J. Dairy Sci. 100:2577-2581.

Pringle, J. H., and M. Fletcher. 1983. Influence of substratum wettability on attachment of freshwater bacteria to solid surfaces. Appl. Environ. Microbiol. 45:811-817.

Rosmaninho, R., and L. F. Melo. 2006. Calcium phosphate deposition from simulated milk ultrafiltrate on different stainless steel-based surfaces. Int. Dairy J. 16:81-87.

Rosmaninho, R., O. Santos, T. Nylander, M. Paulsson, M. Beuf, T. Benezech, S. Yiantsios, N. Andritsos, A. Karabelas, and G. Rizzo. 2007. Modified stainless steel surfaces targeted to reduce fouling-Evaluation of fouling by milk components. J. Food Eng. 80:1176-1187.

Sandu, C., and R. Singh. 1991. Energy increase in operation and cleaning due to heat-exchanger fouling in milk pasteurization. Food Technol. 45:84-91.
Shah, R. K., E. C. Subbarao, and R. A. Mashelkar. 1988. Heat Transfer Equipment Design. CRC Press, Boca Raton, FL.

Sharma, M., and S. Anand. 2002. Characterization of constitutive microflora of biofilms in dairy processing lines. Food Microbiol. 19:627-636

Tsibouklis, J., M. Stone, A. A. Thorpe, P. Graham, T. G. Nevell, and R. J. Ewen. 2000. Inhibiting bacterial adhesion onto surfaces: The non-stick coating approach. Int. J. Adhes. Adhes. 20:91-96.

Van Asselt, A., M. Vissers, F. Smit, and P. De Jong. 2005. In-line control of fouling. In Heat Exchanger Fouling and Cleaning - Chal lenges and Opportunities. Engineering Conferences International, Kloster Irsee, Germany.

Visser, J., and T. J. Jeurnink. 1997. Fouling of heat exchangers in the dairy industry. Exp. Therm. Fluid Sci. 14:407-424.

Watnick, P., and R. Kolter. 2000. Biofilm, city of microbes. J. Bacteriol. $182 \cdot 2675-2679$.

Wehr, H. M., and J. F. Frank. 2004. Standard Methods for the Examination of Dairy Products. 17th ed. American Public Health Association, Washington, DC.

Zhao, Q. 2004. Effect of surface free energy of graded NI-P-PTFE coatings on bacterial adhesion. Surf. Coat. Tech. 185:199-204. 